\title{
ASPECTOS QUÍMICOS, BIOLÓGICOS E ETNOFARMACOLÓGICOS DO GÊNERO Cassia
}

\author{
Cláudio Viegas Junior*, Amanda de Rezende, Dulce Helena Siqueira Silva, Ian Castro-Gambôa e Vanderlan da Silva \\ Bolzani
}

Instituto de Química, Universidade Estadual Paulista "Júlio de Mesquita Filho", CP 355, 14801-970 Araraquara - SP, Brasil

Eliezer J. Barreiro e Ana Luisa Palhares de Miranda

Faculdade de Farmácia, Universidade Federal do Rio de Janeiro, CP 68006, 21941-590 Rio de Janeiro - RJ, Brasil

Magna Suzana Alexandre-Moreira

Centro de Ciências Biológicas, Universidade Federal de Alagoas, 57020-720 Maceió - AL, Brasil

Maria Cláudia Marx Young

Seção de Bioquímica e Fisiologia de Plantas, Instituto de Botânica, 01061-970 São Paulo - SP, Brasil

Recebido em 4/5/05; aceito em 27/1/06; publicado na web em 11/8/06

\begin{abstract}
ETHNOPHARMACOLOGICAL, BIOLOGICAL AND CHEMICAL ASPECTS OF THE Cassia GENUS. Species of Cassia are widely distributed in tropical and subtropical regions throughout the world, and have been extensively investigated chemically and pharmacologically. They are known to be a rich source of phenolic derivatives, most of them with important biological and pharmacological properties. Some Asian, African and Indian tribes use these species as a laxative, purgative, antimicrobial, antipyretic, antiviral and anti-inflammatory agent. Among a number of other classes of secondary metabolites, such as anthracene derivatives, antraquinones, steroids and stilbenoids, biologically active piperidine alkaloids are an especially important bioactive class of compounds that showed to be restricted to a small group of Cassia species. In this paper we present an overview of the chemical, biological and ethnopharmacological data on Cassia piblished in the literature.
\end{abstract}

Keywords: Cassia; Fabaceae; Leguminosae.

\section{INTRODUÇÃO}

O gênero Cassia (Fabaceae) é constituído por mais de 600 espécies incluindo arbustos, árvores e ervas, distribuídas em regiões tropicais e subtropicais de todo o mundo ${ }^{1}$.

Recentemente, revisões na classificação botânica dos gêneros Cassia e Senna levaram à transposição taxonômica de espécies do gênero Cassia para o táxon Senna. Com a separação das leguminosas em três grupos distintos (Subfamílias Caesalpiniaceae, Mimosaceae e Papilionaceae), o gênero Cassia, agora incluído em Fabaceae (Leguminosae), diminuiu em tamanho; estudos de morfologia floral sustentam a classificação inalterada de muitas espécies, muito embora várias cassias ainda continuem sendo descritas como sinonímias de sennas ${ }^{2}$. Espécies de Cassia, juntamente com aquelas com sinonímia Senna ou com algumas que mudaram para o grupo Senna após o novo sistema de classificação taxonômica adotado, constituem um dos maiores gêneros da família Fabaceae.

Em 1999, Agarkar e Jadge ${ }^{1}$ publicaram uma pequena revisão descrevendo 10 espécies de Cassia quanto às suas indicações populares e composição química. Além deste, vários trabalhos destacam espécies como C. auriculata, C. occientalis, C. obtusifolia, C. tora, C. alata, C. angustifolia, C. autifolia, C. nodosa, C. sophera, C. torosa, $C$. nigrigans e $C$. cinnamon, $C$. fistula por sua utilização popular em algumas regiões da Índia, Ásia e África, como laxativos e purgativos, sendo que estudos fitoquímicos e farmacológicos com algumas destas espécies comprovaram também propriedades antibacteriana $^{3-5}$, antifúngica ${ }^{3-5}$, hepatoprotetora ${ }^{6}$ e antimalárica ${ }^{7,8}$, o que demonstra o potencial farmacológico deste gênero vegetal.

Atualmente, cerca de 30 espécies vêm sendo estudadas e relatadas como fontes ricas em derivados fenólicos, antracênicos e

*e-mail: clauvieg@posgrad.iq.unesp.br antraquinônicos, como C. fistula ${ }^{1,9,10}$, C. torosa $^{11-14}$ e C. sophera ${ }^{15-17}$, descritos como as substâncias responsáveis pela atividade dos extratos de várias espécies medicinais (Tabela 1) utilizadas na Índia, Paquistão, Ceilão, Egito e vários outros países como purgativos, mas que também apresentam atividades antimicrobiana, bactericida, antiulcerogênica, anti-inflamatória, dentre outras aplicações ${ }^{1,3,4,6,9}$.

Nos ecossistemas brasileiros, particularmente na Mata Atlântica, o gênero Cassia é muito freqüente, sendo que na região sudeste algumas espécies são bastante apreciadas devido à beleza de suas flores e, por consequiência, muito utilizadas como plantas ornamentais ${ }^{18}$. Algumas espécies como Cassia acutifolia, $C$. angustifolia e $C$. fistula são bastante usadas na medicina tradicional como purgativos ${ }^{4}$. C. fistula, também conhecida como chuvade-ouro ou simplesmente Senna, é muito apreciada pela beleza de seus cachos de flores amarelas e pelas propriedades laxativas de suas vagens, folhas e flores ${ }^{4}$. Além da ação laxativa ${ }^{4,19}$, esta planta também é indicada em diversos países para tratamento de infecções bacterianas ${ }^{4,7}$, reumatismo e lesões cutâneas ${ }^{19}$ (Tabela 1).

Esta revisão reúne dados etnofarmacológicos, biológicos (Tabela 1), farmacológicos (Tabela 2) e químicos (Figuras 1-8) descritos na literatura para espécies do gênero Cassia (sinonímia Senna), complementando trabalho anterior ${ }^{1}$. Algumas das estruturas moleculares apresentadas estão descritas sem a estereoquímica definida, conforme sua citação na literatura.

\section{PRINCIPAIS PROPRIEDADES BIO/FARMACOLÓGICAS E CONSTITUIÇÃO QUíMICA DE ESPÉCIES DO GÊNERO Cassia}

Uma das espécies mais representativas do potencial medicinal deste gênero é C. fistula, intensamente cultivada na Índia, Ceilão, China e Egito, onde tem várias indicações na medicina tradicional, 
Tabela 1. Indicações etnofarmacológicas e biológicas de extratos de Cassia utilizados em medicina popular

\begin{tabular}{|c|c|c|}
\hline Espécie de Cassia & Propriedades etnofarmacológicas e biológicas & Ref. \\
\hline C. abreviata & Contra dores abdominais e dor de dente & 97 \\
\hline C. absus & Antitumoral e anti-asmática & 68 \\
\hline C. acutifolia & Purgativa & 98 \\
\hline C. alata & $\begin{array}{l}\text { Tóxica para o gado, anti-ulcerogênica, contra doenças de pele, eczemas, bronquite, } \\
\text { anti-asmática, antibacteriana e anti-helmíntica }\end{array}$ & $3,94-96$ \\
\hline C. angustifólia & Purgativa, laxativa e contra doenças cutâneas & $86-88$ \\
\hline C. auriculata & $\begin{array}{l}\text { Adstringente, anti-helmíntica, antidiabética, ativa em desordens urinárias, contra } \\
\text { conjuntivites e antibacteriana }\end{array}$ & 3,76 \\
\hline C. biflora & Contra tumores quelóides, picadas de insetos e anti-reumática & 92 \\
\hline C. corymbosa & Mutagênica & 91 \\
\hline C. fistula & $\begin{array}{l}\text { Purgativa, repelente de insetos, anti-reumática, anti-inflamatória, hipoglicemiante, } \\
\text { antidermatite, anti-ofídica, antibacteriana, antiviral, antifúngica }\end{array}$ & $1,3,4,9,19,21$ \\
\hline C. floribunda & Nutricional & 103 \\
\hline C. frandis & Antifúngica & 3 \\
\hline C. grandis & Purgativa, anti-anêmica, adstringente, expectorante, sedativa & 90,91 \\
\hline C. holosericea & Antimicrobiana & 31 \\
\hline C. itálica & Purgativa, contra gota, inibidor biliar, anti-reumática e parasiticida & 93 \\
\hline C. jahni & Purgativa & 48,77 \\
\hline C. kleinii & Purgativa, hepatoprotetora & 100,101 \\
\hline C. laevigata & $\begin{array}{l}\text { Contra dores de ouvido, alopécia, doenças biliares, cólera, expectorante, purgativa, } \\
\text { uso oftálmico }\end{array}$ & 102 \\
\hline C. multijuga & Antibiótica, contra infecções dérmicas e uso oftálmico & 78,79 \\
\hline C. nigrigans & Anti-ulcerogênica, antidiarrêica, vermífuga, anti-reumática, contraceptiva & 24 \\
\hline C. noname & Diurética, tônica & 75,82 \\
\hline C. obtusa & Antipirética, antidiabética, antidiarréica, uso oftálmico e contra doenças cutâneas & 99 \\
\hline C. obtusifolia & $\begin{array}{l}\text { Purgativa, diurética, aumenta acuidade visual, contra doenças oculares e hepatite, } \\
\text { muito ativa contra larvas de mosquitos }\end{array}$ & $73-75$ \\
\hline C. occidentalis & $\begin{array}{l}\text { Purgativa, tônica hepática, bactericida, antipirética, antitumoral, expectorante, } \\
\text { anti-inflamatória, diurética, antifúngica, neurotóxica para bovinos }\end{array}$ & $3,85,120$ \\
\hline C. petersiana & $\begin{array}{l}\text { Anti-sífilis, bactericida, antiviral, antitussígena, antipirética, contra gonorréia, } \\
\text { purgativa, contra dores estomacais, anti-helmíntica, contra infecções cutâneas, inseticida }\end{array}$ & $3,33,80$ \\
\hline C. pumila & Purgativa & 89 \\
\hline C. purpúrea & Antimicrobiana & 31 \\
\hline C. putibunda & Antimicrobiana & 34 \\
\hline C. roxburghii & Antimicrobiana & 31 \\
\hline C. siamea & Purgativa & $10,70,71,108$ \\
\hline C. siebereiana & Tóxica & 72 \\
\hline C. singueana & Anticonvulsivante, anti-ofídica, contra dores estomacais, constipação, gonorréia & 69 \\
\hline C. spectabilis & Citotóxica, tóxica & $49,52-57,65,67$ \\
\hline C. tora & $\begin{array}{l}\text { Diurética, anti-astênica, antibacteriana, contra doenças cutâneas e eczemas, } \\
\text { correção da visão }\end{array}$ & $3,75,83,84$ \\
\hline C. torosa & Contra picadas de insetos, tônica, digestiva & $11-14,30$ \\
\hline C. trachypus & Antimicrobiana & 81 \\
\hline C. zeylanicum & Anti-ulcerogênica e anti-alérgica & 1 \\
\hline
\end{tabular}

como descritas na Tabela 1. Os extratos de várias partes desta planta são utilizados por algumas tribos indianas como agente anti-ofídico e no tratamento de infecções ${ }^{3,4}$ (Tabela 1). As folhas desta espécie apresentam atividades laxativa, purgativa e anti-reumática ${ }^{19}$ e o suco das folhas é utilizado em eripselas e doenças cutâneas ${ }^{19}$ (Tabela 2). Estudos das frações de extratos de várias partes dessa planta demonstraram atividade significativa ${ }^{4}$ contra Escherichia coli, Klebsiella aerogenes, Proteus vulgaris e Pseudomonas aerogenes (bactérias gram-negativas), em dosagens entre 1000-5000 ppm e utilizando o cloranfenicol ( $30 \mu \mathrm{g} / \mathrm{disco})$ como padrão positivo. Estes dados ressaltaram a importância desta planta como um potencial antibiótico natural ${ }^{4}$. A capacidade hepatoprotetora deste extrato foi demonstrada por uma fração rica em antraquinonas e esteróides obtida por fracionamento em alumina. Esta fração foi administrada em ratos com danos hepáticos induzidos por $\mathrm{CCl}_{4} \mathrm{e}$ foi capaz de reverter significativamente as lesões hepáticas ${ }^{19}$.

No Nepal, C. fistula é uma espécie endêmica e a medicina tradicional local utiliza seu fruto para tratamento do reumatismo e da inflamação. Devido a estas indicações, o extrato metanólico de seus frutos foi avaliado quanto à atividade inibitória de mediadores próinflamatórios, como os leucotrienos. A inibição da biossíntese de $\mathrm{LTB}_{4}$ em leucócitos polimorfonucleares bovinos foi efetiva $\left(\mathrm{CI}_{50}=\right.$ $38 \mu \mathrm{g} / \mathrm{mL})$ e de modo dose-dependente. Em outro ensaio, este extrato também foi capaz de inibir a peroxidação de lipídios em fosfolipídeos cerebrais bovinos, o que indicou sua atividade antioxidante $^{20}$. Gupta e colaboradores ${ }^{9}$ avaliaram a atividade antitumoral das sementes de $C$. fistula em linhagens de carcinoma de Erlich. Os resultados indicaram claramente atividade antitumoral 
por um mecanismo ainda desconhecido. A utilização desta planta na Indonésia como repelente de insetos estimulou um outro estudo, envolvendo a purificação de proteínas de defesa, que demonstrou atividade inibitória de protease associada à atividade antifúngica e repelente de insetos ${ }^{21}$.

$\mathrm{O}$ extrato das folhas de $C$. occidentalis, que é indicado como anti-inflamatório ${ }^{6}$ e bactericida ${ }^{3}$, consta de uma lista de plantas selecionadas para controle de doenças tropicais devido às indicações em alguns países africanos como antimalárica ${ }^{7,8}$ (Tabela 2). Estudos de inibição do crescimento de Plasmodium falciparum revelaram a atividade inibitória do extrato em concentrações de 6-600 $\mu \mathrm{g} / \mathrm{mL}$, quando comparado ao cloridrato de quinina ${ }^{7}$. Outros estudos farmacológicos confirmaram que o extrato diclorometânico das folhas de $C$. occidentalis possui atividade antimalárica in vitro, sendo capaz de inibir até $81 \%$ do desenvolvimento do parasita. Por outro lado, há relatos de que cada parte da planta possui atividade e aplicação distintas. Em particular, infusões das folhas são utilizadas em alguns países africanos como purgativo, diurético e como loção ocular ${ }^{8}$; quando fervidas, as folhas são úteis também no tratamento da febre ${ }^{8}$ (Tabela 1). A presença abundante de derivados antracênicos nos extratos estudados indicou que tais substâncias poderiam ser as responsáveis por tais atividades ${ }^{7,8}$. Em especial a 1,8-diidroxi-antraquinona (1) (Figura 1) foi considerada uma dos constituintes ativos por apresentar atividade antimalárica in vitro ${ }^{22}$, o que confirmou os resultados obtidos por Tona e colaboradores ${ }^{8}$.

As folhas e raízes de $C$. nigricans, muito comuns na medicina tradicional nigeriana, são indicadas para tratamento de úlceras gástricas ${ }^{23}$, disfunções gastrointestinais, dor reumatóide e como contraceptivo $^{24}$; no Senegal e na Guinea Francesa é utilizada como vermífugo $^{23}$ (Tabelas 1 e 2). Entretanto, não há relatos na literatura que validem tais atividades, o que estimulou Nwafor e Okwuasaba ${ }^{24}$ a investigarem o extrato das folhas quanto à atividade antidiarrêica e anti-ulcerogênica. Modelos farmacológicos baseados na indução de lesão gástrica por etanol e indometacina revelaram a capacidade do extrato em reverter tal lesão de modo dose-dependente, aparentemente por mobilização de prostaglandinas na mucosa gástrica. Por outro lado, os resultados obtidos em vários experimentos sugerem que o extrato estudado é capaz de atuar como inibidor das funções gastrointestinais, mobilidade e secreção, efeito que pode ser relacionado à ativação do sistema $\alpha_{2}$-adrenoceptor e pode resultar no controle da diarréia ${ }^{24}$. A análise fitoquímica do extrato das folhas de $C$. nigrigans revelou a presença de taninos, saponinas e flavonóides, substâncias conhecidas por afetarem a integridade de membranas ${ }^{21}$. Os taninos são vasoconstritores, mas principalmente sua adstringência está relacionada à prevenção de desenvolvimento de úlcera por precipitação de microproteínas que, por sua vez, formarão uma película protetora contra enzimas proteolíticas ${ }^{25}$. Os flavonóides podem atuar na prevenção da úlcera por aumentarem a resistência capilar e melhorar a microcirculação ${ }^{26}$.

Algumas comunidades indígenas indianas utilizam as sementes de $C$. italica, uma erva perene de regiões subtropicais e áridas, como purgativa (Tabela 1). Estudos fitoquímicos relataram a ocorrência de senosídeos ${ }^{27,28}$, carboidratos, taninos, saponinas ${ }^{27}$, flavonóides ${ }^{29}$ e antraquinonas ${ }^{28}$ nas vagens e folhas dessa planta.

Outra espécie de alto valor medicinal é C. torosa. No Japão, muitos trabalhos foram realizados com várias espécies nativas e exóticas de Cassia, com objetivo de validar suas propriedades medicamentosas e isolar os metabólitos ativos. Na medicina popular japonesa, as folhas frescas dessa planta são utilizadas no tratamento de picadas de insetos ${ }^{11}$, como digestivo, tônico e antídoto ${ }^{30}$ (Tabela 1). O estudo fitoquímico das sementes, raízes e folhas de $C$. torosa levou ao isolamento de diversos flavonóides, hidroantracenos, lactonas naftalênicas e antraquinonas ${ }^{11-14,30}$. Destes constituintes, algumas

antraquinonas, biantraquinonas glicosiladas e flavonas foram os constituintes responsáveis pelas atividades mencionadas ${ }^{11-13}$.

Estudos sobre a atividade anti-alergênica do torosasídeo A (2) ${ }^{13}$, torosídeo B (3), torosacrisona-8-O-6"-malonil- $\beta$-gentiobiosídeo (4) e torosacrisona 8 - $O$-gentiobiosídeo $(\mathbf{5})^{12}$ (Figura 1 ) confirmaram a forte atividade inibitória de $\mathbf{3}$ e moderada de $\mathbf{4}$ e $\mathbf{5}$ sobre leucotrienos $\mathrm{B}_{4}, \mathrm{C}_{4}, \mathrm{D}_{4}$ e $\mathrm{E}_{4}$ liberados em peritônio de $\operatorname{ratos}^{12,13}$.
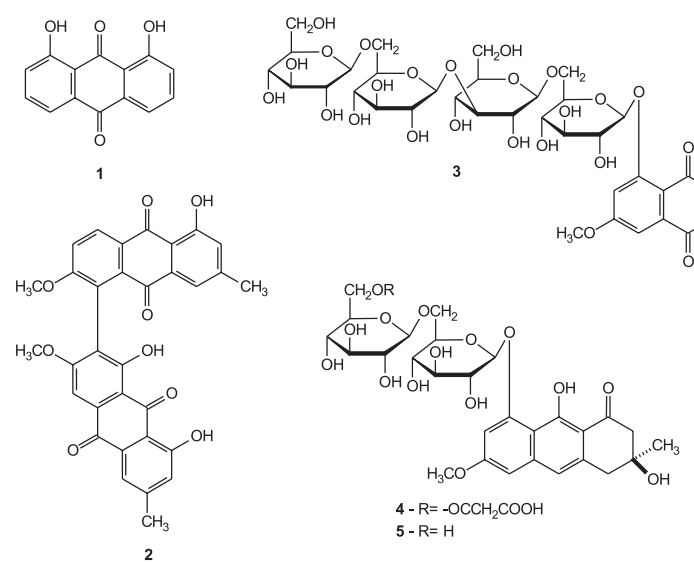

Figura 1. Substâncias bioativas isoladas de C. occidentalis $e$ C. torosa

Das flores e folhas desta planta foram isolados a fissiona (6), (-)-floribundona-2 (7), (-)-floribundona-1 (8), torosanina-9,10quinona (9), 5,7-diidroxicromona (10), crisoeriol (11), torosaol-III (12), torosaflavona C (13) e torasaflavona D (14, Figura 2). Ensaios utilizando culturas de tecidos demonstraram a atividade citotóxica pronunciada da quinona $9\left(\mathrm{ED}_{50}=2,4 \mu \mathrm{g} / \mathrm{mL}\right)$, da bitorosacrisona $12\left(\mathrm{ED}_{50}=1,8 \mu \mathrm{g} / \mathrm{mL}\right)$ e da flavona $13\left(\mathrm{ED}_{50}=2,74\right.$ $\mu \mathrm{g} / \mathrm{mL}$ ) contra linhagens de células $\mathrm{KB}^{14,30}$ (Tabela 2).
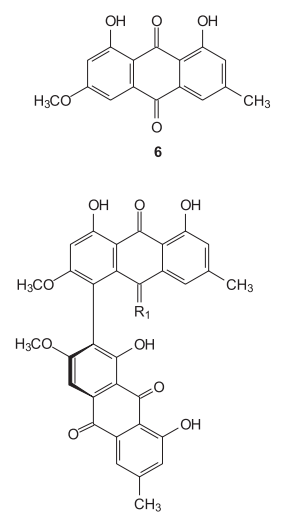

$\mathrm{CH}_{3}$
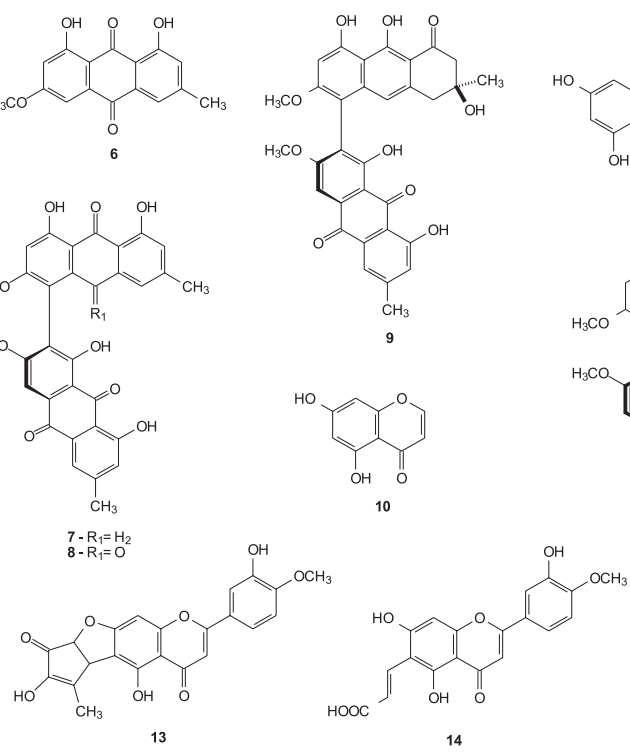

Figura 2. Metabólitos ativos presentes nas flores e nas folhas de C. torosa

Várias espécies da subfamília Caesalpinoidae foram coletadas no Paquistão e submetidas à avaliação das atividades antibacteriana e antifúngica ${ }^{31}$. Dez espécies de Cassia foram avaliadas na concentração de $400 \mu \mathrm{g} / \mathrm{mL}$ e, de modo geral, todos os extratos metanólicos (na maioria ricos em flavonóides e outros compostos fenólicos) foram eficientes na inibição de bactérias e fungos. Os extratos 
metanólicos de $C$. angustifolia e $C$. alata, ricos em terpenos e quinonas, respectivamente, demonstraram $100 \%$ de inibição no crescimento de Staphylococcus pyogenes e Corynebacterium diptheriae e o de C. fistula inibiu em $100 \%$ a cultura de Candida albicans ${ }^{31}$.

As protobutinidinas $\mathbf{1 5 - 1 7}$ (Figura 3), uma classe de antocianidinas, foram isoladas de $C$. petersiana ${ }^{33}$ e demonstraram bons resultados quanto à capacidade inibitória de lipases. Dímeros estruturalmente semelhantes também foram obtidas dos frutos de C. noname. Estes compostos e alguns análogos sintéticos foram investigados quanto à atividade inibitória de lipases. Esses resultados evidenciaram que as flavanas simples são mais potentes na inibição de lipases, podendo ainda atuar como inibidoras de crescimento em insetos ${ }^{34}$.
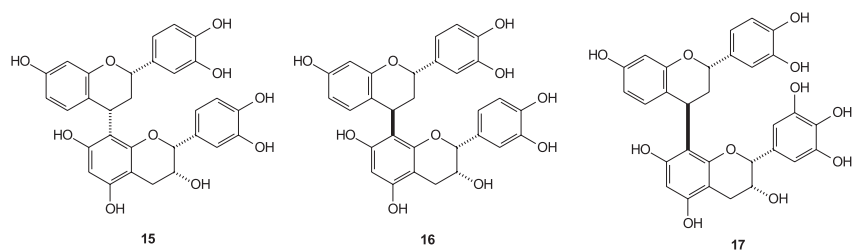

Figura 3. Flavanas diméricas inibidoras de lipases isoladas de C. petersiana

A presença de estilbenóides não é muito comum no gênero Cassia, sendo restritos a C. putibunda ${ }^{35}$ e C. garretiana $^{36,37}$. Esta última, forneceu os cassigaróis A-D (18-21) e cirpusina B (22), bem como os estilbenóides, cassigaróis E-G (23-25) ${ }^{36,37}$ (Figura 4).
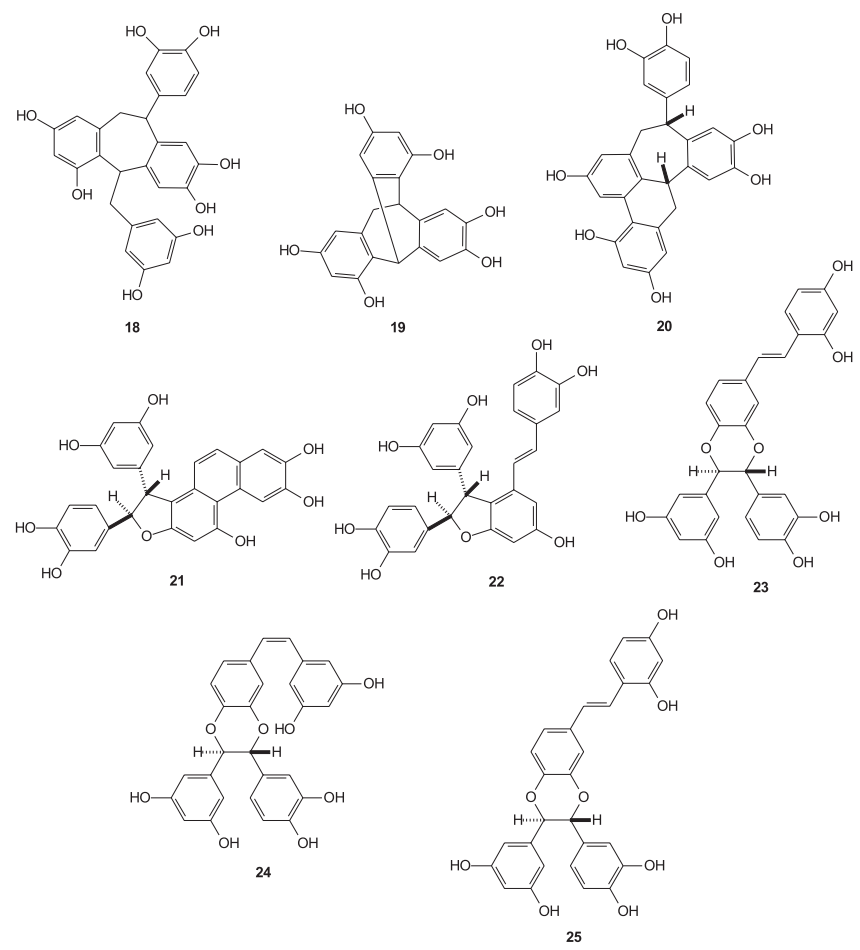

Figura 4. Estilbenóides isolados de C. garretiana

Cassia mimosoides é um exemplo muito peculiar quanto ao seu metabolismo e interação com o ambiente, uma vez que faz parte de um grupo vegetal bastante restrito de plantas, conhecidas como nictinásticas ou plantas que "dormem". À noite, suas folhas se "fecham" e "acordam" ao amanhecer, permanecendo no período diurno com as folhas abertas. Este mecanismo fisiológico é chamado de movimento nictinástico e é controlado por um "relógio bioló- gico" que depende da luminosidade solar. O estudo dos mediadores químicos responsáveis por este movimento permitiu concluir que o movimento nictinástico foliar é controlado por um balanço entre substâncias envolvidas no mecanismo de abertura das folhas. Primeiramente, foi isolado de C. mimosoides, o chelidonato de potássio (26) (Figura 5), substância reconhecida como responsável pela capacidade de fechar as folhas. Mais recentemente, foi isolado pelo mesmo grupo, o 4-O- $\beta$ - $D$-glicopiranosil-cis- $p$-cumarato de cálcio (27) (Figura 5), que parece atuar no processo de abertura foliar. Estes estudos foram guiados por ensaios que utilizam folhas da própria planta e têm servido como sistema para estudo de outras substâncias envolvidas no movimento nictinástico de espécies de outros gêneros vegetais ${ }^{38}$.

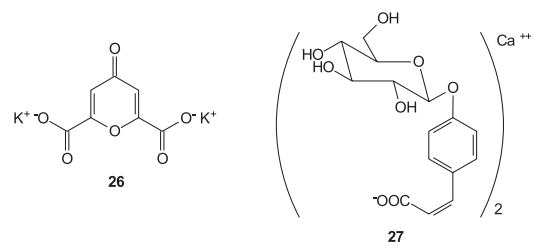

Figura 5. Metabólitos isolados de C. mimosoides responsáveis pelo processo nictinástico

\section{Cassias no Brasil e a bioprospecção de novos fármacos}

A maioria das espécies de Cassia e de Senna que ocorrem no Brasil, tais como C. spectabilis, $C$. carnaval e $C$. excelsa, revelou a presença de alcalóides piperidínicos como constituintes majoritários e, portanto, de grande importância na bioprospecção de novos fármacos. Estas substâncias são particularmente interessantes em virtude das propriedades tóxicas e farmacológicas demonstradas em diversos ensaios in vitro e in vivo realizados com extratos e substâncias puras isoladas de $C$. excelsa e $C$. spectabilis, dentre outras.

Nestas espécies, os metabólitos secundários de maior interesse são os alcalóides do tipo 2,6-dialquil-piperidin-3-óis. Alguns poucos exemplos de outras classes químicas isoladas destas espécies são as flavonas glicosiladas $\mathbf{2 8}$ e $\mathbf{2 9}^{39}$, os ésteres alifáticos de cadeia longa 30 e 30a, a cromona glicosilada $31^{40}$ (Figura 6) e polissacarídeos $^{41}$, obtidos das sementes de C. spectabilis.

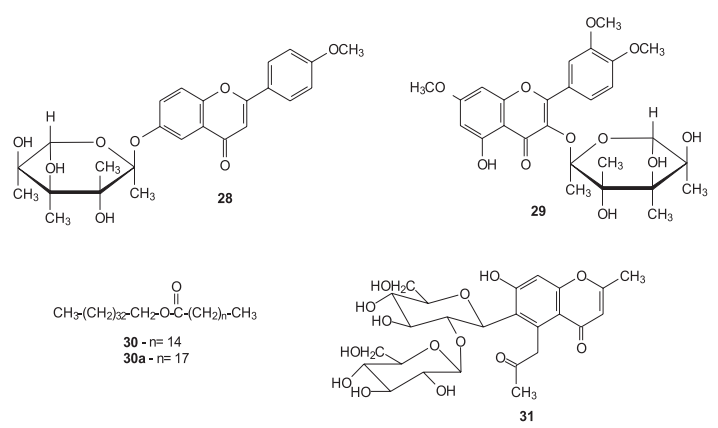

Figura 6. Flavonas, ésteres e cromona isolados das sementes de C. spectabilis

Em 1964, foi isolada pela primeira vez a (-)-cassina (32, Figura 7) presente nas folhas de C. excelsa $a^{42}$. Sua estrutura e estereoquímica foram discutidas e propostas várias vezes, por diferentes grupos ${ }^{43}$.

Mais tarde, Christofidis ${ }^{44,45}$ estudando os extratos das sementes de $C$. spectabilis, re-isolaram a cassina (32) e a carnavalina (33), relatadas por Lythgoe e Vernengo ${ }^{46}$ e suas estruturas corretas foram 
Tabela 2. Propriedades farmacológicas evidenciadas para espécies de Cassia e Senna

\begin{tabular}{|c|c|c|}
\hline Espécie de Cassia & Propriedades farmacológicas & Ref. \\
\hline C. abreviata & Contra doenças venéreas, bactericida & 117 \\
\hline C. acutifolia & Purgativa & 98 \\
\hline C. alata & Antimicrobiana, antifúngica, efeitos tóxicos & 95,116 \\
\hline C. angustifolia & Antitumoral, anti-inflamatória, antibacteriana & $31,88,104$ \\
\hline C. aurantifolia & $\begin{array}{l}\text { Antibiótica, antimalárica, antitumoral, purgativa, ação cardiovascular, neuronal e } \\
\text { bactericida }\end{array}$ & 115 \\
\hline C. auriculata & Bactericida, fungicida e antidiabética & $3,31,107$ \\
\hline C. eucalyptus & $\begin{array}{l}\text { Antibiótica, antimalárica, antitumoral, purgativa, ação cardiovascular, neuronal e } \\
\text { bactericida }\end{array}$ & 115 \\
\hline C. fistula & $\begin{array}{l}\text { Bactericida, anti-inflamatória, hepatoprotetora, fungicida, antitumoral, laxativa, } \\
\text { anti-reumática, antioxidante }\end{array}$ & $4,10,19,21,31,75$ \\
\hline C. hirta & $\begin{array}{l}\text { Antibiótica, antimalárica, antitumoral, purgativa, ação cardiovascular, neuronal, } \\
\text { bactericida }\end{array}$ & 115 \\
\hline C. holosericea & Bactericida, fungicida & 31 \\
\hline C. itálica & $\begin{array}{l}\text { Antibacterina, antitumoral, citotóxica, anti-inflamatória, antipirética, analgésica, } \\
\text { liberadora de prostaglandinas, antiviral }\end{array}$ & $31,32,93$ \\
\hline C. nigrigans & Anti-úlcera, antidiarrêica & 23,24 \\
\hline C. noname & Inibitória de lipases & 34,75 \\
\hline C. obtusifolia & Antiagregante plaquetária, anti-histamínica & $74,75,106$ \\
\hline C. occidentalis & Bactericida, fungicida, antiviral, hepatoprotetora, antimalárica & $\begin{array}{l}3,6,8,31,32 \\
76,113-115\end{array}$ \\
\hline C. petersiana & Inibidora de lipases & 37 \\
\hline C. purpúrea & Bactericida, fungicida & 31 \\
\hline C. putibunda & Citotóxica & 35 \\
\hline C. roxburghii & Bactericida, fungicida & 31 \\
\hline C. siamea & Bactericida, fungicida, antiviral, antioxidante & $31,71,105$ \\
\hline C. singueana & Bactericida & 105 \\
\hline C. singueana & Contra doenças venéreas, bactericida & 117 \\
\hline C. spectabilis & Analgésica, anti-inflamatória, inibitória de superóxido, anestésica & $50,51,53,57,66,103$ \\
\hline C. tora & $\begin{array}{l}\text { Hepatoprotetora, citoprotetora, fungicida, bactericida, antimutagênica, } \\
\text { anti-inflmatória }\end{array}$ & $\begin{array}{c}4,75,76,84 \\
109-112,118,119\end{array}$ \\
\hline C. torosa & Citotóxica, anti-inflamatória & 37,57 \\
\hline
\end{tabular}

propostas. Também foram isoladas a (-)-6-iso-carnavalina (34), a (-)-espectalinina (35), 6-iso-cassina (36) e a (+)-espectalina $(37)^{47}$ (Figura 7). Em 1971, a cassina e a carnavalina foram identificadas nas flores de $C$. jahni, usada como purgativo nos Andes Venezue$\operatorname{lanos}^{48}$ (Tabela 1).

Cassia spectabilis é a espécie de Cassia nativa do Brasil que tem apresentado a maior diversidade de alcalóides piperidínicos ${ }^{49}$ e vários efeitos farmacológicos dessas substâncias vêm sendo confirmados ${ }^{50-53}$.

Na busca por substâncias potencialmente ativas e candidatas a fármacos antineoplásicos, Bolzani e colaboradores ${ }^{49}$ estudaram a atividade de alcalóides piperidínicos isolados das folhas de $C$. spectabilis no reparo do DNA de linhagens mutantes de $S$. cerevisae. Foi a primeira vez que um estudo foi dirigido para tal atividade, tendo sido isolados 7 alcalóides: (-)-espectalina (38), leptofilina-A (39), 3-acetil-leptofilina-A (40), a leptofilina-B (41), a (-)espectalinina (35), a carnavalina (33) e a 6-iso-carnavalina (34) (Figura 7). Destes, os compostos 38-40 inibiram seletivamente o desenvolvimento das linhagens mutantes de S. cerevisiae, demonstrando citotoxidade seletiva ${ }^{49,54-56}$.

Alguns autores associam a importância biológica de alguns tipos de alcalóides piperidínicos hidroxilados com sua semelhança estrutural com carboidratos, denominando-os aza-açúcares. Estes alcalóides capazes de mimetizar monossacarídeos, devido à semelhança estrutural da subunidade açúcar do substrato natural, onde o átomo de oxigênio é substituído por nitrogênio, são largamente dis-

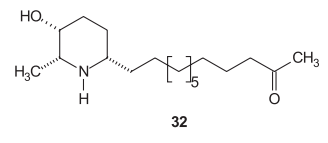<smiles>CC(O)CCCNCCC1CCC(O)CN1</smiles><smiles>CC(O)CCCCCC1CCC(O)CN1</smiles><smiles>CC(O)CCCNCCC1CCC(O)[C@H](C)N1</smiles><smiles>CC(=O)CCCCCC1CCC(O)C(C)N1</smiles><smiles>CC(=O)CCCCCC1CCC(O)[C@H](C)N1</smiles><smiles>CC(=O)CCCCCC1CCC(O)C(C)N1</smiles><smiles>CC1NC(CCCCCCC(O)O)CCC1O</smiles><smiles>CC1NC(CCCCCCC(O)O)CCC1O</smiles><smiles>CC1NC(CCCCCCO)CCC1O</smiles>

Figura 7. Alcalóides piperidínicos isolados de C. spectabilis $e$ C. jahni

tribuídos em plantas e microorganismos ${ }^{57-59}$. Compostos com estas características passaram a receber atenção especial no planejamento de novos fármacos seletivos, em virtude das características estruturais singulares que têm fundamentado sua classificação por alguns autores como compostos híbridos carboidrato-lipídicos. Isto se 
deve à similaridade estrutural da cadeia alifática ao fosfolipídio de membrana, a esfingosina (42) 57,60-63 (Figura 8).

Os piperidinóis 2,6-dissubstituídos são um grupo de aza-açúcares ativos, restritos a poucas espécies vegetais dos gêneros Cassia e Prosopis (Leguminosae) (P. Africana ${ }^{57}$ e $P$. Juliflora ${ }^{64}$ ) e que revelaram atividades analgésica ${ }^{57}$, anestésica ${ }^{57}$ e antibiótica ${ }^{57,64}$. Recentemente, alguns alcalóides deste tipo foram também isolados em hidróides marinhos (Corydendrium parasiticum) nos quais exercem função de defesa ${ }^{65}$.

Alguns grupos de pesquisa estudaram, independentemente, a constituição química de extratos de C. spectabilis (sinonímia Senna spectabilis) obtidos no Brasil, na África e Tailândia e isolaram alcalóides piperidínicos diferentes que demonstraram atividades bio/ farmacológicas, reforçando ainda mais o interesse neste tipo de substâncias ${ }^{50-53,66,67}$.

A (-)-espectalina (38) isolada das flores de C. spectabilis $^{51}$ foi avaliada em modelos farmacológicos in vivo, que confirmaram sua potente atividade analgésica periférica, apesar de ser muito tóxica. Aparentemente, sem ação central e com atividade anti-inflamatória pouco significativa, esta substância age por um mecanismo ainda desconhecido, mas que está provavelmente associado a receptores vanilóides $^{50,51}$. Por outro lado, a 3-O-acetil-espectalina (43, Figura 9), presente nas flores e nos frutos da mesma planta ${ }^{51}$, demonstrou atividade analgésica um pouco menor que $\mathbf{3 8}$, entretanto não apresentou nenhum dos efeitos tóxicos agudos observados para (-)-espectalina ${ }^{53}$.

Kamo e colaboradores ${ }^{66}$ conduziram uma pesquisa com plantas africanas na busca por novos inibidores da produção de ânions superóxido, espécies químicas que podem estar associadas à inflamação, câncer e hipertensão. Os estudos guiados por testes em macrófagos demonstraram a capacidade do extrato metanólico de C. spectabilis de suprimir a produção de superóxido. O fracionamento desse extrato levou ao isolamento da espectamina A (44) e B (45, Figura 8), dois alcalóides piperidínicos inéditos, análogos da 6-iso-cassina (36). Estas duas substâncias foram avaliadas em testes com macrófagos e xantina oxidase, o que evidenciou a capacidade de suprimir a produção de superóxido de ambas, embora o composto $\mathbf{4 4}$ tenha sido muito mais ativo que seu análogo $\mathbf{4 5}$.

Na Tailândia, C. spectabilis também é uma planta ornamental e o conhecimento de que suas folhas e sementes contêm alcalóides tipo 3-piperidinóis, muitos dos quais com atividade citotóxica, levaram Sriphong e colaboradores ${ }^{67}$ a investigar a constituição química de suas flores. Neste estudo, foi re-isolada a cassina (32), juntamente com o derivado inédito 3-O-benzoilado 46 e dois novos alcalóides piridínicos, 47 e 48 (Figura 8). Estas substâncias foram submetidas a ensaios de letalidade frente a Artemia salina e de citotoxicidade frente a linhagens de células KB. No ensaio de citotoxicidade, a cassina (32), seu análogo 46 e o $N$-óxido piridínico 48 mostraram-se bastante ativos $\left(\mathrm{CI}_{50}=5,2,3,7 \text { e } 2,0 \mu \mathrm{g} / \mathrm{mL} \text {, respectivamente }\right)^{67}$.

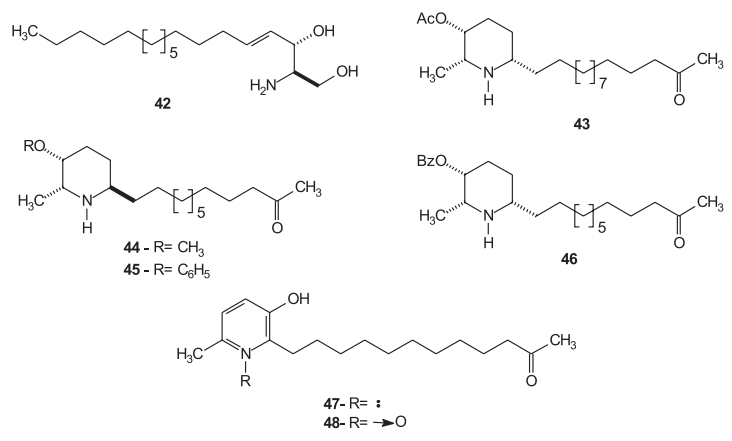

Figura 8. Esfingosina e alcalóides bioativos isolados de C. spectabilis

\section{CONSIDERAÇÕES FINAIS}

Espécies do gênero Cassia revelaram uma grande diversidade de substâncias inéditas e bioativas, com padrões moleculares variados. A literatura relata o isolamento de mais de 350 metabólitos secundários em espécies deste gênero distribuídas em regiões tropicais e subtropicais de várias partes do mundo. Estes estudos evidenciaram a ocorrência de substâncias de várias classes, sendo as antraquinonas, flavonóides e outros compostos fenólicos os constituintes mais freqüentes na maioria das espécies.

Estudos de validação dos dados etnofarmacológicos confirmaram inúmeras indicações populares para diversas espécies de Cassia, incluindo atividade anti-ulcerogênica, antibacteriana, antifúngica, anti-inflamatória, antipirética e analgésica. Por serem bastante raros e responsáveis por atividades farmacológicas importantes, os alcalóides piperidin-3-óis 2,6-dissubstituídos merecem destaque, uma vez que são muito abundantes em pelo menos três espécies da família Fabaceae-Caesalpinioideae.

Cassia spectabilis mostrou-se uma fonte valiosa de alcalóides piperidínicos e piridínicos com características carboidrato-lipídicas, dada sua natureza híbrida constituída por um núcleo $N$-heterocíclico hidroxilado polar e uma cadeia alifática hidrofóbica. Desta espécie já foram isolados e identificados cerca de 20 alcalóides, incluindo alguns inéditos, que vêm sendo alvo de estudos farmacológicos sem precedentes na literatura. $\mathrm{O}$ padrão molecular singular apresentado por estes derivados deve ser responsável pelo largo espectro de atividades farmacológicas, incluindo analgesia ${ }^{50}$, citotoxicidade $^{51,52,67}$, atividade anti-inflamatória ${ }^{51}$ e inibitória de superóxido ${ }^{66}$.

O interesse pela investigação farmacológica dessa classe de compostos vem estimulando vários grupos de pesquisa a desenvolverem metodologias sintéticas que possibilitem sua obtenção em quantidades superiores àquelas produzidas pelas fontes naturais, mas com elevado controle e rendimento estereoquímicos.

A identificação, por alguns autores, da natureza hídrida dessas substâncias, que a princípio reforçaria uma característica lipofílica desejável em vários mecanismos de ação, aliada à semelhança com os aza-açúcares, trouxe uma nova forma de investigação, sobretudo na busca por derivados antivirais e antitumorais. A contínua identificação de novos metabólitos de Cassia, aliada aos novos métodos de avaliação farmacológica e biológica em projetos de bioprospecção de fármacos está sendo determinante na reavaliação de vários extratos vegetais, objetivando a busca por novas classes químicas, a identificação de metabólitos ativos e, preferencialmemte, seletivos a determinados alvos biológicos.

\section{AGRADECIMENTOS}

Ao Programa Biota-FAPESP, à FAPESP e ao CNPq pelos financiamentos à pesquisa e pelas bolsas concedidas.

\section{REFERÊNCIAS}

1. Agarkar, S. V.; Jadge, D. R.; Asian J. Chem. 1999, 11, 295.

2. http://www.blackwoodconservation.org; http://www.zimbabweflora.co.zw; //www.mgonline.com/cassiafistula.html, acessadas em Setembro 2005.

3. Samy, R. P.; Ignacimuthu, S.; J. Ethnopharmacol. 2000, 69, 63.

4. Samy, R. P.; Ignacimuthu, S.; Sen, A.; J. Ethnopharmacol. 1998, 62, 173; Asseleih, L. M. C.; Hernandez, O. H.; Sanchez, J. R.; Phytochemistry 1990, 29, 3095.

5. Palamichamy, S.; Amala, B.; Nagaragan, S.; Fitoterapia 1991, 62, 249.

6. Jafri, M. A.; Subhani, M. J.; Javed, K.; Singh, S.; J. Ethnopharmacol. 1999, 66, 355.

7. Tiwari, R. D.; Misra, G. R.; Planta Med. 1985, $28,182$.

8. Tona, L.; Ngimbi, N. P.; Tsakala, M.; Mesia, K.; Cimanga, K.; Apers, S.; Bruyne, T. D.; Pieters, L.; Totté, J.; Vlietinck, A. J.; J. Ethnopharmacol. 1999, 68, 193 
9. Gupta, V.; Agrawal, A.; Singh, J.; Tiwari, H. P.; Indian J. Chem., Sect. B. Org. Chem. Incl. Med. Chem. 1989, 28, 282; Maresh, V. K.; Sharma, R.; Singh, R. S.; J. Nat. Prod. 1984, 47, 733.

10. Kuo, Y-H.; Lu, P-H.; Wein, Y-S.; J. Nat. Prod. 2002, 65, 1165.

11. Kitanaka, S.; Ogata, K.; Takido, M.; Chem. Pharm. Bull. 1989, 37, 2441.

12. Kanno, M.; Shibano, T.; Takido, M.; Kitanaka, S.; Chem. Pharm. Bull. 1999, 47, 915.

13. Kitanaka, S.; Takido, M.; Phytochemistry 1995, 39, 717; Takido, M.; Kitanaka, S.; Takahashi, S.; Tanaka, T.; Phytochemistry 1982, 21, 425.

14. Kitanaka, S.; Takido, M.; Chem. Pharm. Bull. 1994, 42, 2588; Kitanaka, S.; Takido, M.; Phytochemistry 1982, 21, 2103.

15. Joshi, T.; Dass, A.; Pandey, S.; Shukla, S.; Phytochemistry 1985, 24, 3073; Dass, A.; Joshi, T.; Shukla, S.; Phytochemistry 1984, 23, 2689.

16. Malhotra, S.; Misra, K.; Planta Med. 1982, 46, 247.

17. Malhotra, S.; Misra, K.; Phytochemistry 1982, 21, 197.

18. Lorenzi, H; Árvores Brasileiras: manual de identificação e cultivo de plantas arbóreas do Brasil, $2^{\text {a }}$ ed., Plantarum: Nova Odessa, 1998, vol. 1.

19. Bhakta, T.; Mukherjee, P. K.; Mukherjee, K; Banerjee, S.; Mandal, S. C.; Maity, T. K.; Pal, M.; Saha, B. P.; J. Ethnopharmacol. 1999, 66, 277.

20. Sunil, K. K. C.; Müller, K.; Phytoter. Res. 1998, 12, 526.

21. Gupta, M.; Mazumder, U. K.; Ath, N.; Mukhopadhyay, D. K.; J. Ethnopharmacol. 2000, 72, 151.

22. Cimanga, K.; De Bruyne, T.; Pieters, L.; Turger, C. A.; Vlietinck, A. J.; J. Nat. Prod. 1997, 60, 688

23. Akah, P. A.; Orisakwe, O. E.; Gamaniel, K. S.; Shittu, A.; J. Ethnopharmacol. 1998, 62, 123.

24. Nwafor, P. A.; Okwuasaba, F. K.; Fitoterapia 2001, 72, 206.

25. Aguwa, C. N.; Nwago, S. O.; Nig. J. Pharm. Sci. 1988, 4, 16.

26. John, T. A.; Onabanjo, A. O.; J. Ethnopharmacol. 1990, 29, 87.

27. Sharma, H. K.; Daiya, K. S.; Chauhan, D. D.; J. Econ. Taxon. Bot. 1982, 3,230 .

28. Jain, S. C.; Sharma, R. A.; Jain, R.; Fitoterapia 1996, 67, 82; Jain, S. C.; Sharma, R. A.; Jain, R.; Plant Physiol. Biochem. 1997, 24, 43.

29. El-Sayed, N. H.; Dooh, A. M.; El-Khrisy, E. A. M.; Mabry, T. J.; Phytochemistry 1992, 31, 2187.

30. Kitanaka, S.; Takido, M.; Chem. Pharm. Bull. 1991, 39, 3254.

31. Ali, M. S.; Azhar, I.; Amtul, Z.; Ahmad, V. U.; Usmanghani, K.; Fitoterapia 1999, 70, 299.

32. Jain, S. C.; Jain, R.; Sharma, R. A.; Capasso, F.; J. Ethnopharmacol. 1997, $58,135$.

33. Coetzee, J.; Mciteka, L.; Malan, E.; Ferreira, D.; Phytochemistry 1999, 52 , 737; Coetzee, J.; Mciteka, L.; Malan, E.; Ferreira, D.; Phytochemistry 2000 53,795 .

34. Hatano, T.; Yamashita, A.; Hashimoto, T.; Ito, H.; Kubo, N.; Yoshiyama, M.; Shimura, S.; Itoh, Y.; Okuda, T.; Yoshida, T.; Phytochemistry 1997, $46,893$.

35. Messana, I.; Ferrari, F.; Cavalcanti, M. S. B.; Morace, G.; Phytochemistry 1991, 30, 708.

36. Baba, K.; Kido, T.; Maeda, K.; Taniguchi, M.; Kozawa, M.; Phytochemistry 1992, 31, 3215 .

37. Baba, K.; Kido, T.; Taniguchi, M.; Kozawa, M.; Phytochemistry 1994, 36, 1509 .

38. Ueda, M.; Ohnuki, T.; Yamamura, S.; Phytochemistry 1998, 49, 633.

39. Singh, M.; Singh, J.; Z. Naturforsch, B: Chem. Sci. 1985, 40, 550.

40. Singh, M.; Singh, J.; Z. Naturforsch, B: Chem. Sci. 1984, 39, 1425.

41. Kapoor, V. P.; Taravel, F. R.; Joseleau, J-P.; Milas, M.; Chanzy, H.; Rinaudo, M.; Carbohydr. Res. 1998, 306, 231.

42. Highet, R. J.; J. Org. Chem. 1964, $29,471$.

43. Highet, R. J.; Highet, P. F.; J. Org. Chem. 1966, 31, 1275.

44. Christofidis, I.; Welter, A.; Jadot, J.; Tetrahedron 1977, 33, 977.

45. Christofidis, I.; Welter, A.; Jadot, J.; Tetrahedron 1977, 33, 3005.

46. Lythgoe, D.; Vernengo, M. J.; Tetrahedron Lett. 1977, 12, 1133.

47. Rice, W. Y.; Coke, J. L.; J. Org. Chem. 1966, 31, 1010.

48. Mendez, A. M.; Phytochemistry 1971, 10, 2255.

49. Bolzani, V. S.; Gunatilaka, A. A. L.; Kingston, D. G. I.; Tetrahedron 1995, 51,5929

50. Alexandre-Moreira, M. S.; Viegas Jr., C.; Bolzani, V. S.; Barreiro, E. J.; Miranda, A. L. P.; Planta Med. 2003, 69, 795.

51. Viegas Jr., C.; Tese de Doutorado, Universidade Estadual Paulista, Brasil, 2003.

52. Viegas Jr., C.; Bolzani, V. S.; Furlan, M.; Young, M. C. M.; Tomazela, D.; Eberlin, M. N.; Barreiro, E. J.; J. Nat. Prod. 2004, 67, 908.

53. Viegas Jr., C.; de Rezende, A.; Barreiro, E. J.; Bolzani, V. S.; Resumos da $48^{a}$ Jornada Farmacêutica da UNESP, Araraquara, Brasil, 2001; Viegas Jr., C.; Barreiro, E. J.; Bolzani, V. S.; Resumos da 25 Reunião Anual da Sociedade Brasileira de Química, Poços de Caldas, Brasil, 2002; Viegas Jr., C.; Moreira, M. S. A.; Barreiro, E. J.; Bolzani, V. S.; Resumos da 25
Reunião Anual da Sociedade Brasileira de Química, em Poços de Caldas, Brasil, 2002; Viegas Jr., C.; Bolzani, V. S.; Barreiro, E. J.; Miranda, A. L. P.; Resumos da $26^{a}$ Reunião Anual da Sociedade Brasileira de Química, Poços de Caldas, Brasil, 2003.

54. Bolzani, V. S.; Gunatilaka, A. A. L.; Kingston, D. G. I.; J. Nat. Prod. 1995, $58,1683$.

55. Bolzani, V. S.; Trevisan, L. M. V.; Izumizawa, C. M.; Young, M. C. M.; J. Braz. Chem. Soc. 1996, 7, 157.

56. Bolzani. V. S.; Young, M. C. M.; Furlan, M.; Cavalheiro, A. J.; Araújo, A. R.; Silva, D. H. S.; Lopes, M. N.; An. Acad. Bras. Ci. 1999, 71, 181.

57. Cook, G. R.; Beholz, L. G.; Stille, J. R.; Tetrahedron Lett. 1994, 35, 1669.

58. Toyooka, N.; Yoshida, Y.; Momose, T.; Tetrahedron Lett. 1995, 36, 3715.

59. Banba, Y.; Abe, C.; Nemoto, H.; Kato, A.; Adachi, I.; Takahata, H.; Tetrahedron: Asymmetry 2001, 12, 817.

60. Pahl, A.; Oetting, J.; Holzkamp, J.; Meyer, H. H.; Tetrahedron 1997, 57, 7255 .

61. Momose, T.; Toyooka, N.; Tetrahedron Lett. 1993, 34, 5785.

62. Inoue, S.; Tsuruoka, T.; Niida, T.; J. Antibiot. 1966, 19, 288.

63. Inoue, S.; Tsuruoka, T.; Ito, T.; Niida, T.; Tetrahedron 1968, 24, 2125.

64. Ahmad, V. U.; Basha, A.; Haque, W.; Z. Naturforsch, B: Chem. Sci. 1978, 33,347 .

65. Linquist, N.; Shigematsu, N.; Pannell, L.; J. Nat, Prod. 2000, 63, 1290.

66. Kamo, T.; Machara, K.; Sato, K.; Hirota, M.; Heterocycles 2003, 60, 1303.

67. Sriphong, L.; Sotanaphun, U.; Limsirichaikul, S.; Wetwitayaklung, P.; Chaichantipyuth, C.; Pummangura, S.; Planta Med. 2003, 69, 1054.

68. Rao, R. V. K.; Rao, J. V. L. N. S.; Vimaladevi, M.; J. Nat. Prod. 1978, 42 , 299

69. Mutasa, S. L.; Khan, M. R.; Jewers, K.; Planta Med. 1990, 56, 244.

70. Wagner, H.; El-Sayyad, S. M.; Seligmann, O.; Chari, V. M.; Planta Med. 1978, 33, 258.

71. Thongsaard, W.; Chainakul, S.; Bennet, G. W.; Marsden, C. A.; J. Pharm. Biochem. Anal. 2001, 25, 853.

72. Waterman, P. G.; Faulkner, D. F.; Planta Med. 1979, 37, 178

73. Kitanaka, S.; Takido, M.; Phytochemistry 1981, 20, 1951; Yang, Y-C.; Lim, M-Y.; Lee, H-S.; J. Agric. Food. Chem. 2003, 51, 7629

74. Kitanaka, S.; Nakayama, T.; Shibano, T.; Ohkoshi, E.; Takido, M.; Chem. Pharm. Bull. 1998, 46, 1650

75. Hatano, T.; Uebayashi, H.; Ito, H.; Shiota, S.; Suchiya, T.; Yoshida, T.; Chem. Pharm. Bull. 1999, 47, 1121.

76. Lohar, D. R.; Garg, S. P.; Chawan, D. D.; J. Indian Chem. Soc. 1981, 58, 989.

77. Rao, G. N.; Kumar, P. M.; Dhandapani, V. S.; Rama, Krisshna, T. R.; Hayashi, T.; Fitoterapia 2000, 71, 82.

78. Singh, J.; Phytochemistry 1982, 21, 1177

79. Dubey, P.; Gupta, P. C.; Planta Med. 1980, 38, 165

80. Msonthi, J. D.; Planta Med. 1984, 42, 114

81. Monache, F. D.; D'Albuquerque, I. L.; Chiappeta, A. D. A.; De Mello, J. F.; Phytochemistry 1992, 31, 259.

82. Kitanaka, S.; Takido, M.; Phytochemistry 1992, 31, 2927.

83. Wong, S-M.; Wong, M. M.; Seligmann, O.; Wagner, H.; Phytochemistry 1989, 28, 211.

84. Choi, J. S.; Jung, J. H.; Lee, H. J.; Lee, J. H.; Nag, S. S.; Phytochemistry 1995, 40, 997.

85. Singh, M.; Singh, J.; Planta Med. 1985, 51, 525.

86. Lemli, J.; Cuveele, J.; Planta Méd. 1978, 33, 293.

87. Kinjo, J.; Ikeda, T.; Watanabe, K.; Nohara, T.; Phytochemistry 1994, 37, 1685.

88. Cuéllar, M. J.; Giner, R. M.; Recio, M. C.; Máñez, S.; Riós, J. L.; Fitoterapia 2001, 72, 221.

89. Mukherjee, K. S.; Chakraborty, C. K.; Chatterjee, T. P.; Bhattacharya, P.; J. Indian Chem. Soc. 1989, 66, 66

90. Verma, R. P.; Sinha, K. S.; Indian J. Chem., Sect. B: Org. Chem. Incl. Med. Chem. 1995, 34, 75; González, A. C.; Bernejo, J.; Valencia, E.; Planta Med. 1996, 62, 176.

91. Ferreira, I. C. F. S.; Vargas, V. M. F.; Phytoter. Res. 1999, 13, 397.

92. Meenarani; Kalidhar, S. B.; J. Indian Chem. Soc. 1998, 75, 386.

93. Kazmi, M. H.; Malik, A.; Hameed, S.; Akhtar, N.; Ali, S. N.; Phytochemistry 1994, 36, 761.

94. Yadav, S. K.; Kalidhar, S. B.; Planta Med. 1994, 60, 601

95. Sodipo, O. A.; Effraim, K. D.; Emmagun, E.; Phytoter. Res. 1998, 12, 431.

96. Lans, C.; Harper, T.; Georges, K.; Bridgewater, E.; Preventive Vet. Med. 2000, 45, 201; Ibrahim, D.; Osman, H.; J. Ethnopharmacol. 1995, 45, 151.

97. Malan, E.; Swinny, E.; Ferreira, D.; Steynberg, P.; Phytochemistry 1996, $41,1209$.

98. Mascolo, N.; Capasso, R.; Capasso, F.; Phytoter. Res. 1998, 12, S143.

99. Sekar, M.; Prasad, K. J. R.; Sidduraju, P.; Janardhanan, K.; Fitoterapia 1999, 70,330 . 
100. Anu, S. J.; Rao, J. M.; Phytochemistry 2001, 57, 583.

101. Anu, S. J.; Rao, J. M.; Phytochemistry 2002, 59, 425.

102. Jones, L.; Bartholomew, B.; Latif, Z.; Sarker, S. D.; Nash, R. J.; Fitoterapia 2000, 71, 580

103. Vadivel, V.; Janardhanan, K.; Food Chem. 2001, 73, 209.

104. Müller, B. M.; Kraus, J.; Franz, G.; Planta Med. 1989, 55, 536.

105. Endo, M; Naoki, H.; Tetrahedron 1980, 36, 2449.

106. Yun-Choi, H. S.; Kim, J. H.; J. Nat. Prod. 1990, 53, 630.

107. Sabu, M. C.; Subburaju, T.; J. Ethnopharmacol. 2002, 80, 1.

108. Wong, S-M.; Wong, M. M.; Seligmann, O.; Wagner, H.; Planta Med. 1989, $55,276$.

109. Kitanaka, S.; Takido, M.; Chem. Pharm. Bull. 1991, 39, 3254.

110. Mukherjee, P. K.; Saha, K.; Saha, B. P.; Pal, M.; Phytoter. Res. 1996, 10, 521.

111. Choi, J. S.; Lee, H. J.; Park, K-Y.; Ha, J-O.; Kang, S. S.; Planta Med. 1997, 63,11 .
112. Maity, T. K.; Mandal, S. C.; Mukherjee, P. K.; Saha, K.; Das, J.; Pal, M.; Saha, B. P.; Phytoter. Res.1998, 12, 221.

113. Hatano, T.; Mizuta, S.; Ito, H.; Yoshida, T.; Phytochemistry 1999, 52, 1379.

114. Bin-Hafeez, B.; Ahmad, I.; Haque, R.; Raisuddin, S.; J. Ethnopharmacol. 2001, 75, 13.

115. Evans, C. E.; Banso, A.; Samuel, O. A.; J. Ethnopharmacol. 2002, 80, 21.

116. Khan, M. R.; Kihara, M.; Omoloso, A. D.; Fitoterapia 2001, 72, 561.

117. Kambizi, L.; Afolayan, A. J.; J. Ethnopharmacol. 2001, 77, 5.

118. Koyama, J.; Morita, I.; Tagahara, K.; Ogata, M.; Mukainaka, T.; Tokuda, H.; Nishino, H.; Cancer Lett. 2001, 170, 15.

119. Koyama, J.; Morita, I.; Tagahara, K.; Aqil, M.; Phytochemistry 2001, 56 , 849.

120. Barros, C. S. L.; Ilha, M. R. S.; Bezerra Jr., P. S.; Langohr, I. M.; Kommers, G. D.; Pesq. Vet. Bras. 1999, 19, 68. 